\title{
INMIGRANTES ARGENTINOS EN SAN DIEGO Y TIJUANA. ESTRATEGIAS DE ADAPTACIÓN A UN ESTILO DE VIDA TRANSFRONTERIZO
}

\section{ARGENTINE IMMIGRANTS IN SAN DIEGO AND TIJUANA. ADAPTATION STRATEGIES TO A CROSS-BORDER LIFESTYLE}

Jose Navarro-Conticello* y Guillermo Alonso-Meneses**

Resumen: Este artículo propone revisar, a la luz del concepto de transfronterizo, algunas categorías usuales en los estudios migratorios - como transnacional, espacio transnacional y migración transnacional, ciudadanía post-nacional y circularidad migratoria- partiendo de las estrategias de adaptación de una comunidad minoritaria de inmigrantes en una región marcada por una de las fronteras internacionales más cruzadas/vigiladas. Mediante la aplicación de entrevistas semiestructuradas, son analizadas las experiencias de 20 mujeres y hombres argentinos residentes en San Diego y Tijuana, a ambos lados de la frontera Estados Unidos/México. Las y los entrevistados demuestran conocer y practicar el estilo de vida transfronterizo propio de esta región, asignando significados al cruce de la frontera y estableciendo negociaciones identitarias entre su cultura de origen y la/s cultura/s de incorporación en cuatro ámbitos: trabajo, familia, relaciones sociales y costumbres.

* Candidato a Doctor, Doctorado en Ciencias Humanas, Instituto de Estudios Humanísticos y Facultad de Psicología, Universidad de Talca, Talca, Chile. Correo electrónico: jonavarro@utalca.cl

El autor agradece a CONICYT por financiar sus estudios de doctorado en Chile (CONICYT-PFCHA/Doctorado Nacional/2017-Folio No 21170178).

** Profesor-Investigador Titular, El Colegio de la Frontera Norte, Tijuana, México. Correo electrónico: gui@colef.mx.

Ambos autores agradecen a las/os dos revisoras/es por sus observaciones, que han ayudado a mejorar sustantivamente la primera versión de este documento. 
Palabras clave: migración argentina; estrategias de adaptación; transfronterizo; estilo de vida transfronterizo; frontera San Diego/Tijuana.

Abstract: This article proposes to review, in the light of the concept of cross-border, some categories that are usual within migration studies —such as transnational, transnational space and transnational migration, post-national citizenship, and circular migration - starting from the strategies of adaptation of a minoritarian community of immigrants in a region shaped by one of the most crossed/patrolled international borders. Through the application of semi-structured interviews, the experiences are analized of 20 Argentine women and men living in Diego and Tijuana, on both sides of the US/Mexico border. Respondents demonstrate both knowing and practising this region's cross-border lifestyle, assigning meanings to the act of crossing the border, and displaying identity negotiations between their culture of origin and the culture/s of incorporation around four nodes: work, family, social relations, and customs.

Key words: argentine migration; adaptation strategies; crossborder; cross-border lifestyle; San Diego/Tijuana border.

\section{INTRODUCCIÓN}

Este artículo propone revisar algunas categorías usuales en la producción académica sobre migraciones a la luz del concepto de transfronterizo, partiendo del estudio de las estrategias adaptativas a la/s cultura/s de incorporación por parte de inmigrantes argentinos residentes a ambos lados de la frontera Estados Unidos/México, más específicamente en las áreas metropolitanas de San Diego y Tijuana.

Se espera que la agencia de miembros de una comunidad nacional minoritaria en su adaptación a un contexto marcado por una de las fronteras internacionales más cruzadas y vigiladas sirva como evidencia para relativizar o precisar algunos conceptos de uso extendido como transnacional, espacio transnacional y migración transnacional (Glick-Schiller, Basch y Szanton-Blanc, 1992; Portes, Guarnizo, \& Landolt, 1999; Levitt, 2009; Vertovec, 2009; Nieswand, 2011), ciudadanía post-nacional (Basok, 2004) y circularidad migratoria (López \& Godenau, 2015). 
Desde hace décadas este tipo de constructos vienen siendo aplicados a regiones específicas como la frontera Estados Unidos-México (Vila, 2000; Ceballos, 2001) o fronteras de Sudamérica (Karasik y Benencia, 1998; Grimson, 2000; Caggiano, 2007; Kralich, Benedetti y Salizzi, 2012; Renoldi, 2014). Aun así, parte de la academia los utiliza sin atender a dinámicas transfronterizas locales y micro-locales como las que aborda este trabajo, que contienen un componente transnacional y experiencias migratorias internacionales en un corto radio espacial.

\section{MARCO TEÓRICO}

En cierta bibliografía especializada, el concepto de transfronterizo o cross-border suele ser empleado como sinónimo de transnacional (Van Houtum \& Van der Velde, 2004; Waldinger, 2015). Incluso en trabajos críticos de enfoques sesgados como el nacionalismo metodológico (Wimmer \& Glick-Schiller, 2002), la distinción entre ambos términos permanece ausente. Problemas similares se observan con otras categorías de uso extendido en los estudios migratorios, como ciudadanía post-nacional o circularidad migratoria, que sugieren, respectivamente, un giro desde la concepción estadocéntrica hacia un reconocimiento más individual de los derechos de ciudadanía, y una tendencia a la movilidad en ambos sentidos entre país de origen y de residencia (Basok, 2004; López \& Godenau, 2015).

El uso de estos conceptos suele estar acompañado de una visión global de la migración que remite a movilidades de amplio radio espacial, donde el país de origen y el de destino suelen ser geográficamente distantes, mientras que los movimientos de menor alcance que habilitan los territorios fronterizos —e involucran muchas veces a migrantes provenientes de un tercer país - permanecen en gran parte inexplorados. Pero aun entre quienes reconocen las particularidades de la migración en contextos de frontera existen sesgos en la delimitación teórico-conceptual de los sujetos que habitan estas regiones o la/s cultura/s que se va/n construyendo allí. En la producción académica sobre la frontera Estados Unidos-México, la figura del cruzador de fronteras prevalece sobre la de quienes no pueden o no desean cruzarlas, y a menudo las y los mexicanos o mexicano-estadounidenses son entendidos como los sujetos transfronterizos por excelencia, 
invisibilizando el rol de otras culturas y comunidades nacionales en la construcción sociocultural de ese espacio (Vila, 2000, 2001).

No obstante, existen autoras y autores cercanos a los estudios urbanos y de frontera que toman en consideración la complejidad y heterogeneidad de estos territorios, donde se entrecruzan rasgos de asimetría y polarización con factores de continuidad o permeabilidad. Así, Alonso $(2009,2016)$ defiende la necesidad de manejar categorías como transfronterizo o situaciones de transfronteridad para pensar las experiencias migratorias en microespacios socioculturales o arenas locales, mientras que Herzog $(2000,2003)$ habla tanto de metrópolis como de planeación y cooperación transfronterizas y más recientemente (Herzog \& Sohn, 2014) de la metrópolis transnacional en la era global, observando que el fenómeno está más extendido de lo que podría presuponerse.

En línea con estos esfuerzos de conceptualización/contextualización, este artículo parte del reconocimiento de que en torno a las fronteras se modelan formaciones socioculturales complejas y situadas, indisociables de los actores y las prácticas que en ellas tienen lugar. Así, se propone analizar las fronteras como "complejos sistemas de filtración y diferenciación, en vez de rígidos contenedores territoriales o restos existentes de un pasado" (Heyman, 2011, p. 81).

Retomando a Alonso (2016), el concepto de frontera utilizado en este trabajo incluye tanto el límite jurídico-político-administrativo entre dos estados -en este caso, Estados Unidos/México y específicamente San Diego/Tijuana- como las diversas fronteras simbólicas que se superponen con aquel, diferenciando/comunicando configuraciones socioculturales tales como gringo/mexicano, protestante/ católico, seguridad/inseguridad, prohibido/permitido. Esto habla del carácter procesual y dinámico de las fronteras y de las culturas, identidades y estilos de vida que estas albergan.

En cuanto al concepto de transfronterizo, aquí se entiende como tal a los espacios, fenómenos, grupos y sujetos que en su funcionamiento habitual aprovechan las ventajas y desventajas propiciadas por la frontera. El estilo de vida transfronterizo refiere a las formas y contenidos específicos que caracterizan a las prácticas e intercambios desplegados por quienes habitan espacios marcados por la frontera, sean originarios de ellos o no, como en este estudio. En tal sentido, lo transfronterizo se diferencia de lo transnacional en que el primero involucra a la frontera como un elemento central, activo y omnipresente, mientras que el segundo refiere a intercam- 
bios y movilidades que ocurren a través o más allá de las fronteras entre estados nacionales, sin que sea necesaria la participación de las fronteras como factor central (Alonso, 2016).

En ese contexto, lo que en este artículo se entiende por estrategias de adaptación son los mecanismos conscientes o inconscientes mediante los cuales los migrantes se adaptan — en diversos grados y de diferentes maneras- a la/s cultura/s de incorporación, mientras que lo que aquí se denomina negociaciones identitarias corresponde a un tipo específico de mecanismos de adaptación consistente en transar ciertos elementos o rasgos de identificación —identidadentre el individuo y su cultura de origen y otros que el sujeto asume como propios de la/s cultura/s de incorporación. Esta segmentación analítica entre cultura de origen y cultura/s de incorporación no está asociada con una concepción esencialista de la cultura ni con la idea de necesaria coincidencia entre identidad nacional y cultura. Como han explicado Anderson (1983) y Segato (2007), las identidades nacionales son convenciones imaginadas que descansan en la ilusión de mismidad a partir de la construcción y definición de alteridades. No obstante, estas nociones se utilizan aquí en el sentido de la identificación de cada sujeto con aquello que cada uno asume y narrativiza como propio de su cultura de origen o bien perteneciente a la/s cultura/s de incorporación.

\section{MARCO CONTEXTUAL}

Tijuana, según el último censo nacional, está entre las cinco mayores ciudades de México, con 1.559.683 habitantes, aunque las proyecciones censales para 2020 hablan de más de 2 millones de habitantes (INEGI, 2019). Si se suman los 1,6 millones de su vecina San Diego (US CENSUS BUREAU, 2010) se obtiene la conurbación más populosa de la frontera México-Estados Unidos, que a 220 kilómetros -3 horas en automóvil por la Interestatal 5- se conecta con Los Ángeles, el área metropolitana con mayor número de inmigrantes mexicanos en Estados Unidos. Este corredor condensa la mayor cantidad de hispanohablantes después de la Ciudad de México.

Tijuana/San Diego forman el par de lo que se ha llamado twin cities, ciudades gemelas o border cuates (Herzog, 2009), una vieja metáfora-concepto que ilumina una realidad metropolitana con 
continuidades urbanas/estructurales, parecida a otras que existen en distintas regiones de Las Américas (Herzog, 2015). Con la especificidad de estar atravesadas por una de las fronteras internacionales más cruzadas y vigiladas, lo que introduce la perspectiva del control de las fronteras y las nuevas configuraciones transfronterizas y transnacionales (Ribas, 2011; Baumann, Lorenz \& Rosenow, 2011; Herzog \& Sohn, 2014; Castles, Ozkul \& Arias Cubas, 2015; Alonso, 2016). Esta conurbación de facto, caracterizada por los controles fronterizos/aduaneros y las dinámicas socioeconómicas que catalizan, puede ser un ejemplo de dinámicas sub-nacionales que se ensamblan multiescalarmente en la globalización (Sassen, 2009, p. 570), aunque con particularidades propias que se entienden a la luz del Tratado de Libre Comercio para América del Norte o TLCAN/ NAFTA, reformulado y rebautizado en 2018 como Tratado México, Estados Unidos y Canadá o T-MEC/USMCA y otros vectores de desarrollo asociados a la globalización.

Otra especificidad de esta región es su estilo de vida transfronterizo. Allí hay ciudadanos y ciudadanas con visas y pasaportes que a diario cruzan la frontera como si se desplazaran de un barrio a otro, residen parte de la semana en Estados Unidos y parte en México o trabajan en un país y duermen en el otro. Pero el fenómeno trasciende a los border commuter workers. Hay estadounidenses que parte de la semana viven en el área de Los Ángeles y otra parte en localidades costeras al sur de Tijuana, entre Rosarito y Ensenada, a 100 kilómetros de la frontera. Estas experiencias migratorias resultan de un proceso histórico de más de un siglo y son encarnadas por personas que a menudo, si mexicanas, tienen doble nacionalidad/ciudadanía, y si estadounidenses o residentes en Estados Unidos, poseen pasaporte para cruzar a México. Generalmente, las y los mexicanos son "centauros identitarios", mitad mexicanos, mitad estadounidenses (Alonso, 2009).

En los últimos años, además, la frontera San Diego/Tijuana ha sido escenario de una batalla contra la migración indocumentada. Fue este el lugar donde, en 2018, Donald Trump escenificó la elección del modelo de su muro. Es que, después del 11-S, el reforzamiento del control fronterizo puso un cepo a los flujos migratorios irregulares de México a Estados Unidos (Passel \& D’Vera, 2011) y Tijuana pasó de ser en el último tercio del siglo XX el trampolín para cruzar sin documentos al país del norte a convertirse en el siglo XXI en la ciudad que recibe el mayor número de expulsados por Estados Unidos (ICE, 2017). 
Las dinámicas transfronterizas también propiciaron que desde fines de los años 60 del siglo XX en las ciudades vecinas de los estados de California y Texas se deslocalizaran distintas empresas transnacionales, cuya experiencia les había enseñado que una forma de abaratar los costos de producción era trasladarlas fuera - pero cerca- de Estados Unidos. Así, las compañías transnacionales o multinacionales, que inspiraron el concepto de transnacionalismo aplicado a los estudios de migración (Glick-Schiller, Basch y Szanton-Blanc, 1992), descubrieron las ventajas de mudar sus fábricas o maquilas a México. Ahora mismo, empresas estadounidenses, japonesas, chinas o coreanas tienen ejecutivos e ingenieros viviendo en San Diego y cruzando diariamente a trabajar en Tijuana. También en esta región la red eléctrica está interconectada -México le vende electricidad a Estados Unidos- y el gasoducto de la estadounidense Sempra Energy nace en el municipio mexicano de Ensenada y desemboca en los Estados Unidos, porque las leyes de California prohíben una terminal de licuefacción de gas natural en sus costas.

La región San Diego/Tijuana manifiesta rasgos de la globalización en dos de sus polarizaciones principales: la sociedad que excluye (Dahrendorf, 1996) y la sociedad-red que articula un nuevo paradigma económico (Castells, 2009). Este enclave -recordar que San Diego alberga una inmensa base naval y es sitio de prácticas de las más recientes tecnologías bélicas- se ha convertido - especialmente a partir de la entrada de Estados Unidos a la Segunda Guerra Mundial- en un laboratorio experimental de los intereses capitalistas globalizadores-desregulatorios, que someten a estrés el Estado-nación y afectan la vida de las personas. Así, mientras en Tijuana es patente la violencia del narco, San Diego exhibe el éxito de la economía digital en sus áreas de innovación tecnológica. Los automóviles de lujo, adquiridos a precios bajísimos en comparación con otros lugares de México y Estados Unidos, circulan en San Diego sobre calles y avenidas perfectas, mientras que en Tijuana muchas veces contrastan con senderos de tierra. Antiguos autobuses escolares estadounidenses son las unidades del transporte público por excelencia de Tijuana, las calafias. A ambos lados de la línea se localizan sucursales de las mismas megatiendas comerciales, pero la variedad y los precios son más convenientes en San Diego. Y lo que el norte brinda en términos de bienes de consumo, el sur lo compensa con atención médica de calidad a un precio mucho más bajo -modernas clínicas destinadas a residentes en Estados Unidos- o 
una industria del entretenimiento nocturno que convoca cada fin de semana a miles de sandieguinos a cruzar a Tijuana para disfrutar de placeres censurados en su ciudad.

En este contexto, donde las comunidades mayoritarias son la mexicana, la mexican-american y la estadounidense, la inmigración argentina es minoritaria, pero representa un número no despreciable. Según el último censo, 2.432 argentinas y argentinos residen en San Diego, conformando la novena comunidad latinoamericana más numerosa (US CENSUS BUREAU, 2010). No hay datos oficiales que den cuenta del número exacto de personas de ese origen radicadas en Tijuana, aunque según el conteo más confiable ascienden a 695, constituyendo la quinta comunidad extranjera (Alegría, 2005). De mínima, entonces, habría 3.127 argentinas y argentinos radicados en la región. Sin embargo, no existe información sobre su composición. En cuanto a las y los participantes de este estudio, se advierten perfiles socioeconómicos, etarios y de calificación variados. Tal vez un rasgo compartido por la mayoría sea el período de emigración: 16 de las 20 personas contactadas emigraron después del año 2000 y 10 de ellas lo hicieron entre 2000 y 2003, en coincidencia con la denominada "crisis del corralito" en Argentina. La variedad de perfiles y el período mayoritario de emigración permitiría relacionar los casos analizados con la emigración argentina por motivos económicos de principios del siglo XXI, período donde las crisis económicas, sociales, políticas e institucionales que sacudieron al país impactaron en amplias franjas de las clases medias y bajas argentinas provocando un éxodo, especialmente hacia Europa y Estados Unidos (Novick, 2007).

\section{MÉTODO}

El diseño del estudio fue cualitativo, exploratorio, de corte transversal. El muestreo fue no probabilístico, según conveniencia de los investigadores de acuerdo con los objetivos de investigación y disponibilidad de los sujetos. Los criterios de selección de participantes fueron: nacionalidad argentina, mayores de edad y residentes en el condado de Tijuana o la ciudad de San Diego por al menos un año, mínimo a partir del cual según Blanco (2000) existe una experiencia migratoria significativa y para que una persona sea considerada inmigrante según Naciones Unidas (IOM, 2011). Se buscó una dis- 
tribución proporcional según sexos, rangos etarios y lugar de residencia (Tijuana o San Diego) para captar posibles variaciones de acuerdo con esos factores.

Se aplicó un muestreo tipo "bola de nieve" (Hernández, Fernández y Bautista, 2006): se contactó primero a informantes clave (investigadores expertos en migración residentes en la región Tijuana/San Diego), quienes proporcionaron datos de contacto de argentinas y argentinos radicados a ambos lados de la frontera, quienes sugirieron otros posibles entrevistados y entrevistadas, hasta llegar a un número que permitiera realizar un análisis cualitativo de cierta profundidad.

Así, se entrevistó a 20 personas, 12 hombres y 8 mujeres, 11 residentes en San Diego y 9 radicados en Tijuana, con edades entre 35 y 91 años y entre 2 y 52 años de residencia continuada en el lugar de radicación actual.

Las personas fueron contactadas primero telefónicamente para agendar hora y lugar de un encuentro presencial, luego personalmente se les aplicó una entrevista semiestructurada tipo "historia de vida" (Mallimacci y Giménez, 2006) que tuvo una duración aproximada de entre 1 hora y media y 3 horas. Todas las entrevistas fueron realizadas entre el 18 de mayo de 2015 y el 28 de abril de 2016, en los domicilios o empresas de las y los participantes, restaurantes y cafés de San Diego y Tijuana. Los lugares y horarios fueron escogidos por las personas entrevistadas.

El contenido de las entrevistas fue desgrabado y transcripto. Para resguardar la identidad de las y los participantes, los nombres que se utilizan aquí son ficticios. También se mantuvo textualmente la utilización de argentinismos o expresiones propias del castellano rioplatense que se habla en Argentina, así como otras propias del estilo de vida transfronterizo. Se identificaron hechos significativos en cada historia de vida y se los ordenó alrededor de núcleos temáticos en función de los objetivos de la investigación, como recomienda Sautu (1999, p. 102).

\section{RESULTADOS}

De los relatos se deduce que las personas entrevistadas conocen y practican el estilo de vida transfronterizo de la región San Diego/ Tijuana. En cuanto a sus estrategias de adaptación, demuestran ca- 
pacidad de agencia al establecer negociaciones entre la cultura de origen y la/s cultura/s de incorporación. Y tienen una doble adscripción, transfronteriza y transnacional. La gran mayoría cruzan —con mayor o menor asiduidad - la frontera, y en los pocos casos en que no lo hacen - por no tener permiso legal— se valen de amigos o conocidos para obtener aquello que necesitan del otro lado.

\subsection{Significados asociados al cruce San Diego-Tijuana}

Quienes viven en San Diego, mayoritariamente, dicen cruzar a Tijuana para aprovechar la mayor accesibilidad de servicios sanitarios, tanto en términos económicos como culturales, por compartir la misma lengua con las y los profesionales de la salud y otros códigos simbólicos que asocian diferencialmente a lo "latino" y a lo "gringo".

El dentista [...] allá es infinitamente más barato y tan bueno o mejor que aquí y por lo menos con México es más fácil negociar. Los mexicanos, incluso los médicos, es más fácil negociar con ellos, aquí el médico gringo tiene la imagen de que él es Dios y te ve así, como Dios mira a las hormigas, negritos, chiquititos y pendejos. Allá, en México, no, allá lo hablas con el mismo médico, si no te gusta lo que el tipo te dice, te vas a otro, no se ven ellos como Dios y tú no los ves como Dios, entonces el trato es diferente y por eso mismo me llevo bien con eso (Guido, argentino residente en San Diego, 57 años).

Yo uso la frontera para el médico. Los servicios médicos casi todos los tengo en Tijuana. Mi médico de cabecera, que me conoce bien y te va a decir "Abelardo es hipocondriaco", toda la verdad mía, te va a decir que "le duele esto y se queja" y se va a reír de mí. Bueno, todo, el dentista, que tenés que hacer esas cosas que son terribles y me las hice en Tijuana con un dentista de una amiga (Abelardo, argentino residente en San Diego, 68 años).

El dentista, acá en San Diego, te puede pedir 20 mil o $27 \mathrm{mil}$ dólares [...] Yo fui a hacer una estimación por una limpieza acá y tenía seguro y en total yo no sé de dónde salieron, pero me dicen "16 mil dólares" [...] Fui a Tijuana y creo que me salió 400 o 500 dólares. Y eso con todo, no solamente con el dentista. Allá está lleno de farmacias, en cada cuadra, por lo menos una hay. Si vas con la receta de acá no se puede, pero siempre tienen un médico arriba al que le pueden pedir la receta; hecha la ley, hecha la trampa (Adelmar, argentino residente en San Diego, 91 años). 
Otro de los motivos más frecuentes del cruce a Tijuana por parte de las y los entrevistados asentados en San Diego es el ocio, también asociado a valoraciones de la cultura estadounidense - percibida como más aburrida, fría y rígida, aunque ciertamente más segura- y mexicana -interpretada como divertida, cálida, libre, aunque también más insegura o peligrosa-. Esto se advierte en la narración de Adelmar, quien, además, menciona los usos de la frontera relacionados con la reproducción de las costumbres propias de la cultura de origen.

Nosotros íbamos mucho, nos gustaba ir a visitar. Íbamos hasta la carnicería $[. .$.$] porque había un carnicero que sabía cómo$ los argentinos queríamos la carne para hacer matambre, entonces íbamos hasta allá [...], preguntábamos por el señor este, le decíamos que saque la grasa y todo eso [...] Era fun, era lindo ir a Tijuana [...] Hay lugares en la avenida Revolución, están los boliches, caminás por la calle y ves cómo le están echando la botella de ron a alguien dentro de la boca. Nos gustaba ir a cenar también, las últimas veces íbamos a un lugar en Paseo de los Héroes, un lugar lindo. Íbamos los sábados casi siempre por allá. En esa época, antes del 2000, íbamos bastante y llegaba una visita y también lo llevábamos, era obligatorio llevarlos a otro país, ir a Tijuana (Adelmar, argentino residente en San Diego, 91 años).

\subsection{Significados asociados al cruce Tijuana-San Diego}

Entre quienes residen en Tijuana, el cruce a San Diego es utilizado mayoritariamente para adquirir productos específicos. Si se contrasta con los testimonios anteriores, se aprecia que ambos grupos reproducen en el sentido que les dan a sus prácticas un imaginario donde el lado sur, a pesar de su inseguridad y su desorganización, es apreciado como más humano o afectivamente próximo, mientras que el lado norte, a pesar de su organización y previsibilidad, únicamente alcanza a satisfacer necesidades materiales y utilitarias.

Yo, por ejemplo, pasan dos, tres meses que hay veces que ni cruzo, porque tenés que hacer la cola, ay, qué embole, con eso de tanto trámite de migraciones, nos daba mucha hueva, como dicen acá, sacar la SENTRI [...] y además, como buenos argentinos, no nos bancamos a los yanquis [...] Vamos cuando tenemos que ir de compras pero de ropa, a mí me da hueva tener que hacer las compras del super allá, tenés que hacer la cola, ir hasta allá, cargar todo para casa, si te toca el semáforo rojo [en la aduana] 
tenés que pagar [...] Esa sociedad es peor que ésta. Por lo menos ésta, con todos los defectos que pueda tener, es latina, allá no podés hacer una fiesta, no podés hacer ruido después de las 10 de la noche, tus perros ladran y te hacen una denuncia, le pegaste al perro que te rompió todo el mueble y te denuncian. O sea, es un desastre. Estudios Universal, toda esa cosa, pero volver al sabor latino (Elisa, argentina residente en Tijuana, 50 años).

Por otro lado, es evidente que algunas ventajas asociadas al estilo de vida transfronterizo — como la adquisición de bienes materiales- pueden ser aprovechadas por vivir en la región, más allá de de cruzar o no la frontera efectivamente. Por ejemplo, Mauro y Jesús no están habilitados legalmente para trasladarse de Tijuana a San Diego, pero igualmente consiguen los bienes que necesitan comprar del otro lado de la línea por medio de familiares, conocidos o amigos a quienes se los encargan.

Yo no cruzo, no saqué la visa, yo vivo 100\% acá, pero el tema de la cuestión fronteriza sí me sirve porque tengo, por ejemplo, los hijos de mi esposa que pasan siempre, van y vienen con su papá, si yo necesito cosas se las pido, me las traen y no he estado hasta el momento interesado, en el momento que lo esté, seguramente voy a ir (Mauro, argentino residente en Tijuana, 59 años).

Por ahí sí, si ocupo algo sí, pido que me lo traigan del otro lado, por ejemplo, mando a pedir los tenis, ya sabes, tener calidad del otro lado es mejor que la de aquí, o quizás a veces el precio, pero es muy raro, en general prefiero lo de aquí (Jesús, argentino residente en Tijuana, 36 años).

\subsection{Estrategias de adaptación y negociaciones identitarias}

Por otra parte, las estrategias de adaptación al estilo de vida transfronterizo incluyen negociaciones identitarias entre componentes de la propia cultura y rasgos de la/s cultura/s de incorporación. Estas se producen, al menos, en cuatro ámbitos especialmente significativos para las y los participantes: trabajo, familia, relaciones sociales y costumbres.

\subsubsection{El trabajo}

El trabajo aparece vinculado con el crecimiento personal, pero también con negociaciones, interpretaciones o apropiaciones de la/s 
cultura/s de incorporación, respecto de las cuales las y los participantes expresan distintos grados de cercanía o lejanía, destacando algunos elementos y criticando otros. Esto se percibe en el testimonio de Abelardo, quien reside en San Diego pero trabaja en Tijuana, ciudad que dice haber logrado conocer en profundidad y con la que manifiesta haber desarrollado una ligazón afectiva por estar a cargo allí de una agencia de publicidad. También en el de Rosa, una mujer que se dedica a la venta y trueque en puestos callejeros denominados sobrerruedas en del lado mexicano de la línea y swap meet del lado estadounidense.

Yo no quería la frontera, no me gustaba. Pero llegué y me fui quedando. Gracias a Dios, después de muchos años te puedo decir que no hubo un solo día que nos faltó el trabajo, nunca tuve que cortar personal, es muy meritorio eso para una ciudad. Empiezas a aprender que la ciudad más hermosa es la que te brinda mejores oportunidades [...] y Tijuana es una ciudad increíble en ese sentido. Claro, a los dos años, me puse la otra sede en San Diego porque era lógica la conexión [...] Yo acá en Tijuana tomo café, morfo todos los días acá, estoy todo el día acá, tengo eventos acá, no sé, es todo [...] La vi crecer y la conozco toda [...] Yo manejo la cuenta de la Comisión Estatal de Servicios Públicos, que es el agua, y la Comisión Estatal de Servicios, que es el gas, hace 19 años [...] Cada vez que había una inauguración me llevaban a La Morita, el Valle de las Palmas, que parece que fuera otro país $[\ldots]$, conozco $[\ldots]$ lugares donde las casas están colgadas, donde hay mucha libertad para construir [...] y después se caen cuando llueve, ese tipo de cosas que por ejemplo del otro lado no te permitirían [...] En mi casa, del otro lado, para hacer una escalera adentro, en el jardín, tuve que pedir permiso a la municipalidad y vinieron los gringos y "cuanto mide, cuánto va a pesar la escalera", ipara adentro de mi casa! [...] Las multas son terribles (Abelardo, argentino residente en San Diego, 68 años).

Cuando llegábamos al sobrerruedas era una fiesta, nada que ver a los swap meet de aquí. Cuando llegué acá una me dice "ya se va a hacer amigos", pero vine acá a hacer swap meet y ¡una frialdad...! [...] Se armaban su puesto, no te decían ni buenos días [...] En Tijuana era una fiesta cada vez que llegabas al trabajo. Todos mis amigos mexicanos “iey, argentina!" [...] Era una fiesta ir a cada sobrerruedas, teníamos cincuenta plazas y donde fuéramos éramos bien amigos, con las mujeres como con los hombres, y la que tenía niños y nos tocaba puesto, "le dejo mi niño, voy a comprar pizza para todos". Bien familiero. Me gustó mucho (Rosa, argentina residente en San Diego, 65 años). 
La significación del trabajo como vía de adaptación al estilo de vida local es especialmente importante en los hombres, cuyos testimonios se articulan mayoritariamente alrededor de ese eje temático. A Sebastián, músico, tras haber superado el trauma que significaron sus primeras experiencias de cruce fronterizo, y a pesar de que sigue evitando cruzar excepto para hacer compras específicas, hoy vivir en Tijuana le permite utilizar estratégicamente la cercanía de la frontera para expandir su trabajo hacia el mercado norteamericano. Por su parte, a Sixto, Luca y Diego, propietarios de restaurantes especializados en comida argentina en Tijuana, residir en Tijuana les ha posibilitado aprovechar las ventajas competitivas de la región para hacer negocios o abastecerse de productos para sus comercios.

Cuando llegué, Argentina estaba en la lista negra y cada vez que iba a cruzar la frontera, era segunda revisión y por lo menos media hora de preguntas, me llegaron a preguntar hasta a qué secundaria fue mi papá, cosas ridículas y las primeras veces que cruzaba me daba dolor de panza, me descomponía, era realmente traumático. Me tomó muchos años asimilarlo como algo más natural y ahora no me causa conflicto a nivel físico cruzar, me tomó muchos años llegar a no tener ningún problema en cruzar más que la espera. No me han enviado a revisión secundaria, no me preguntan nada, incluso yo, por la actividad que hago, estoy en la lista de invitados de honor del cónsul norteamericano y cada 4 de julio me invitan a la embajada [consulado] y estoy tomando champagne con esa gente y aun así me causaba conflicto, pero bueno, hace ya varios años que empecé a hacer redes con colegas contrabajistas en San Diego, quienes me abrieron las puertas a una red más a nivel nacional de contrabajistas que me ha permitido realmente trascender mucho más que la posición local de San Diego. De hecho, hay una sociedad mundial de contrabajistas que tiene sede en Estados Unidos y yo estoy como representante de Latinoamérica en la mesa directiva de doce personas, y justamente estoy ahí porque yo sí puedo viajar a las reuniones y sin embargo vivo en Latinoamérica y tengo contactos de la frontera para abajo. En ese sentido, vivir en la frontera me abrió las puertas al cien por ciento para todos los Estados Unidos, adentro del mundito chiquito de los contrabajistas, pero voy a cualquiera de los festivales internacionales y me conocen todos y yo conozco a la mayoría, y todo eso ha sido gracias a esto. De hecho, eso me ha redituado en invitaciones, en relaciones que van más allá de la frontera $[\ldots]$, yo siento que tengo una presencia allá a través de 
mis proyectos, sin tener la necesidad de ir, o sea, yo no estoy cruzando ni siquiera todos los meses (Sebastián, argentino residente en Tijuana, 35 años).

Estando todavía en Argentina trabajando como cocinero me presentaron una persona que le decían el mexicano, pero era un argentino que había puesto negocios en México y Miami [...] y me dice "mirá, Sixto, me gustaría que tu cocina traspase las fronteras, me gustaría hacerte una invitación para ir allá”, le digo "bueno", yo no le creía, pasaron casi tres años y medio y me llama por teléfono. "Ya está el restaurante, falta que vengas para acá”. “YY a dónde?” “A Tijuana, México”. Como ya le había dado la palabra, le digo "sí, está bien” [...] y me vine a Tijuana. No conocía nada, $[\ldots]$ no tenía ni noción a dónde iba, lo único que conocía era la persona esta [...] Después esa misma persona me llevó a trabajar en Estados Unidos, me dijo "sabés qué, vente para San Diego, te necesito allá para que me organices el negocio, le digo yo que quería hacer algo por mi cuenta en Tijuana y me dice "no, ahora vente conmigo porque te necesito y tú necesitas, después hacés lo que quieras en México pero ahora tenés que venirte conmigo” y me fui a trabajar allá con él, trabajé allá siete años con él, siempre viviendo aquí en Tijuana, y en el primer mes que yo trabajé allá, renté mi local acá, el primer mes, y de ahí batallé bastante, porque hasta que armé el negocio, hice papeles [...] Fue duro, todos los días a las cinco de la mañana estaba cruzando, me comía una línea de cuatro horas, tres horas. Descansaba un solo día, el domingo (Sixto, argentino residente en Tijuana, 55 años).

Algunas cosas para el local compro, un 10 o 20\% compro de aquel lado, pero casi todo lo compro acá. Mi hermano vive del otro lado, a veces voy una vez a la semana, a veces puedo pasar un mes y no voy ni un día, no me importa. Pero sí vamos para comprar algo y para ir a la casa de mi hermano que vive acá cerca en Chula Vista [...] Yo todavía tengo pasaporte español por parte de mi abuela, paso, llamo por teléfono y veo si voy, no me urge ir, voy y si veo que hay gente me doy vuelta y me voy, no espero dos horas, pero ahora ya este año voy a tener la SENTRI por mi esposa, pasa que ella pasa con la $S E N T R I$ y yo voy caminando (Luca, argentino residente en Tijuana, 41 años).

Mucho, 60\% de lo que yo compro [de mercadería para el restaurante] es del otro lado. Por una cuestión de calidad y precio, las dos cosas. Acá se come todo del otro lado, el pollo este es del otro lado, la tripa de ese chorizo también es del otro lado, el queso, compro casi todo del otro lado (Diego, argentino residente en Tijuana, 56 años). 


\subsubsection{La familia}

La familia es otro de los ámbitos centrales sobre los cuales las y los participantes estructuran discursivamente su adaptación al estilo de vida transfronterizo. Aunque en la mayor parte de los hombres parece tener una importancia subordinada a la del trabajo, mientras que para la mayoría de las entrevistadas las dinámicas familiares constituyen claramente el tema central de sus preocupaciones. En los testimonios de estas mujeres, la migración es analizada en relación con sus impactos en parejas, hijos e hijas. La familia como un conjunto que migra es una figura más presente en las narrativas femeninas que en las masculinas, donde prevalece la idea del trabajo como factor de progreso desde una perspectiva individual.

Primero se vino mi exmarido y después me vine yo con mis dos hijos, de 12 y 15 años, estaban en la adolescencia, estaban como locos, no entendían nada. Al principio querían venirse, pero después... Es una etapa difícil, a mi hijo no se le hizo tan difícil porque empezó la secundaria, conoció a chicos nuevos, todo era nuevo, pero a mi hija se le hizo difícil, lo del padre la tiene bastante loca, la separación [...] Yo trabajo, pero no me alcanza para nada si no me apoya él. Aunque acá uno se arregla, de repente consigue todo usado [...] Él cada tanto depositaba un dinero, recién nos vino a ver, los vino a ver a mis hijos, porque a mí no, en noviembre del año anterior, porque vino la madre a visitarlo (Judith, argentina residente en Tijuana, 49 años).

Los chicos ya estaban en la adolescencia y fíjate cómo habrá sido la crisis, hasta qué punto llegamos a estar ahí, que se nos cerraron todas las puertas, no teníamos opciones, era "te vas" o "te vas a morir, y en la muerte arrastrás a todos los que tenés alrededor". Para poder llegar a México, unos amigos hicieron una vaquita para poder comprar el pasaje de mi marido y para darle un poco de plata para que se moviera, en ese momento se habían juntado para vivir 500 dólares, me dejó 300 a mí porque en mi casa tampoco había plata y él se vino con 200 dólares a México, él dice lo que sufrió el primer tiempo [...] Al año y medio viajamos con los chicos para conocer México, mi hija se quedó para empezar la prepa, porque ya habíamos visto que se iba a atrasar indefectiblemente por los cruces y los pases y las revalidaciones, ella ya estaba en tercer año de secundaria, tenía que pasar. El mayor justo estaba terminando, él estudió en el Carlos Pellegrini, iba a entrar a la universidad, pero con esto de que nos veníamos no entró, yo no lo dejé, para qué si después lo iba a dejar. Ahora 
pienso que tendría que haberlo dejado, ¿no? (Elisa, argentina residente en Tijuana, 50 años).

\subsubsection{Las relaciones sociales}

Un tercer ámbito significativo en la adaptación de las y los entrevistados al estilo de vida transfronterizo son las relaciones sociales, principalmente en dos sentidos: con otros integrantes de la comunidad argentina y con el resto de las y los integrantes de la/s cultura/s de incorporación.

Respecto del primer punto, las personas participantes en este estudio señalan que su relación con otros argentinos y argentinas en el lugar de destino es escasa y, en algunos casos, conflictiva. A pesar de ello, la mayoría indican que han desarrollado acciones para fortalecer los lazos con sus connacionales, conectando a través de ellas su cultura de origen con su experiencia actual.

Yo tenía un amigo en el gobierno argentino [...] y yo le dije "tengo muchos años en la frontera y la Argentina necesita un consulado acá, yo me ofrezco, pongo mis oficinas a disposición del consulado, la atiendo yo". Acá todo el mundo me conoce, cuando yo le platiqué la idea, por ejemplo, al cónsul de España, que es amigo mío, me dijo "sí, hay que hacerlo, yo te hago una carta". Yo me ofrecí, yo quería ser cónsul de Argentina acá, no sé, no prosperó, yo tampoco lo seguí porque cuesta [...], tenés que dejar el laburo, yo no le di el seguimiento oportuno y mi amigo mayormente no pudo hacer nada. Yo trabajo en frontera, no tengo problemas con los idiomas, tengo años de estar acá, me conocen los argentinos de San Diego, que no hay tantos, me conocen los pocos argentinos que hay en Tijuana, tengo buena imagen, buen crédito, no sé, ¿qué más hace falta? Nunca prosperó, pero eso un poco te explica cómo sigo ligado a la Argentina, siempre estoy pendiente (Abelardo, argentino residente en San Diego, 68 años).

Con respecto a las relaciones sociales con otros integrantes de la/s cultura/s de incorporación, la mayoría de las y los entrevistados residentes a ambos lados de la frontera dicen sentirse más afines y tener mejores relaciones con la comunidad mexicana que con las y los estadounidenses o gringos. Aunque en ciertos testimonios también afloran fuertes estrategias de diferenciación respecto de lo que identifican como características propias de la idiosincrasia mexicana que serían divergentes de la argentina. 
Yo soy descendiente de italianos y soy gritona como yo sola, y eso acá choca mucho, a menos que vos entres en la dinámica de ellos [los mexicanos] y empieces a jugar exactamente el mismo juego que ellos. Pero suponte que vos decís "yo me voy a hacer mi lugar muy, muy fuerte", no te estoy diciendo adaptación, te estoy hablando de tener un prestigio muy estable. Para entrar en el juego de ellos tenés que dejar de ser vos mismo. [..] Yo veo las diferencias de relación, el concepto de amistad que manejan en México es totalmente diferente al que se maneja en Argentina; en Argentina la amistad es sagrada, el amigo está en las buenas y en las malas, no es solamente un dicho, está. Y creo que casi todo el mundo ha vivido una experiencia que te demuestra eso. Acá todo es por conveniencia, si me conviene estoy y si no, no, encontrar un amigo que sea un amigo de ley, que cuando te estés ahogando y muriendo meta la mano en el lodo para sacarte, no lo vas a encontrar. Así que es demasiado complejo y te puedo decir, yo estoy muy contenta aquí en Tijuana, pero no es fácil ser extranjero en México (Elisa, argentina residente en Tijuana, 50 años).

\subsubsection{Las costumbres}

Por último, en el ámbito de las costumbres, las y los participantes demuestran establecer negociaciones entre sus hábitos de alimentación, lenguaje y otros rasgos de su cultura de origen para adaptarse al estilo de vida transfronterizo. En ese sentido, exhiben diversas formas de adaptación. En esa gama, es posible encontrar algunos casos en los que las estrategias son complejas e incluyen un cálculo sobre aquellos planos en los que conviene ceder y aquellos en los que es más provechoso reforzar lo propio, calculando costos y beneficios de una u otra opción.

Mi esencia, mi forma de comer, mi hora de comer, mis alimentos, no las negocio. Yo como y ceno todos los días acá y tengo una hija con mi mujer actual que es mexicana, ella come argentino y la mamá es mexicana. La acostumbré. Ella come dulce de leche, banana con dulce de leche, desayuna pan, y tengo otra hija que es nicaragüense, que come gallopinto, que es un plato nicaragüense, con un sándwich de miga [...] Gracias a Dios siempre he estado en la posición que lo he podido hacer, porque si estoy en una casa donde no tengo qué carajo comer y hay tortillita, me tengo que callar la boca y me la tengo que comer, pero si tengo la posibilidad de darme el lujo con una docena de sándwiches en Los Ángeles, que valen nueve dólares, bueno, me los pago o si no me los hago 
yo [...] Yo les aprendí mucho, estudiando a la cultura mexicana y mirándolos, son otra gente, ni mejor ni peor, son diferentes. Cuando quiero obtener un favor, uso todo nuestro carisma argentino. Y cuando necesito algo, por ejemplo, tengo que llevar el auto a arreglar, yo no hablo, tiene que hablar mi mujer mexicana porque a mí me pegan una turreada [...] Acá tenés mucha libertad que a veces la usás para tu bien y a veces para tu mal. A mí me para la policía acá y yo los mando a la c... de su madre, porque tengo contactos y uso eso. Del otro lado no existe eso. Del otro lado no jodés (Diego, argentino residente en Tijuana, 56 años).

Otros entrevistados y entrevistadas exhiben estrategias de adaptación menos activas en términos de conservación de las costumbres propias de la cultura de origen, o más abiertas a la asimilación de los rasgos de la/s cultura/s de incorporación. Esto se nota, inclusive, en la incorporación de entonaciones y formas del habla propias del lugar de acogida. En el caso de Jesús, a pesar de reconocer las costumbres locales como "extrañas", dice haberlas adoptado y, por el modo en que se expresa, es difícil percibir que no es nativo de esta región.

Cuando yo llegué aquí hablando con el tono argentino bien marcado, todos quedaron así, bien raro, este wey, ¿de dónde eres, por qué hablas así? [...] Llegué al frente del negocio y empecé [...] te acostumbras al idioma de aquí, pues, convivo con puros mexicanos [...] Te acoplas [...] Yo me acostumbré mucho más a la comida mexicana. Los restaurantes argentinos sí me gustan, me gusta el mate, sí me gusta. Pero yo convivo con pura gente mexicana. Me preguntan, ¿a cuántos mexicanos les haces tomar mate? Es muy difícil, no los acostumbras, por el sabor, porque está caliente, por la simple razón de tener que compartir la bombilla con ellos. No, ellos tienen unas costumbres muy extrañas, y te acostumbras, a las comidas, a los horarios, a los picantes, yo voy y me siento en un restaurant de comida mexicana y a mí me encanta. Te acostumbras. Ahorita que fui a Argentina, no los pude acostumbrar a ellos ni así un poquito, ni siquiera unos chilitos toreados (Jesús, argentino residente en Tijuana, 36 años).

\section{CONCLUSIONES}

Como se puede deducir de sus relatos, las y los inmigrantes argentinos residentes en las áreas metropolitanas de San Diego y Ti- 
juana demuestran no solo haberse adaptado a la/s cultura/s de incorporación sino también practicar el estilo de vida propio de esa región profundamente marcada por la ineludible presencia de una de las fronteras internacionales más cruzadas y vigiladas que existen $-\mathrm{y}$ las enormes contradicciones, continuidades y asimetrías que esa doble condición de apertura y cierre habilita-. Esta doble adaptación - a una cultura y a un estilo de vida - se advierte especialmente en dos ámbitos singulares de su experiencia, que a su vez se encuentran claramente interconectados: el cruce fronterizo -y sus significados asociados-y las negociaciones identitarias entre componentes o rasgos de aquello que consideran propio de su cultura de origen y otros que perciben como característicos de la/s cultura/s de incorporación.

Respecto del primer ámbito, se aprecia cómo los sujetos practican y significan de manera diferencial el cruce fronterizo internacional de acuerdo con el sentido o la dirección del mismo. Cuando es de norte a sur (San Diego-Tijuana), los motivos mayoritarios están vinculados a aspectos sensibles a sus necesidades más profundas salud-o emociones - ocio, diversión-. Consecuentemente, la carga simbólica que le adosan coincide con cierta idea de proximidad entre la cultura de origen y una de las culturas de incorporación: la "mexicana" o "latina", en oposición a la "gringa", que en general es percibida como distante. En cambio, cuando el cruce es de sur a norte (Tijuana-San Diego), la motivación del cruce es mayormente utilitaria y material —adquisición de bienes específicos- y en varias ocasiones acompañada de una valoración negativa de la cultura estadounidense. Otro aspecto relevante tiene que ver la escasa relevancia que para los — pocos - entrevistados que no están habilitados legalmente para cruzar hacia Estados Unidos parece tener esta limitación, ya que igualmente dicen utilizar la frontera de manera tercerizada - mediante otras personas que les traen del otro lado aquello que necesitan-.

Respecto del segundo ámbito, en el marco de su adaptación a un estilo de vida transfronterizo, las y los inmigrantes argentinos establecen una serie de negociaciones. En ellas se ponen en juego estereotipos y prejuicios, pero también reflexiones que les permiten dar sentido a su experiencia tomando como base identificaciones y diferenciaciones respecto de distintos rasgos de su cultura de origen y la/s cultura/s de incorporación. Estas negociaciones tienen lugar en torno a cuatro ámbitos especialmente significativos para estos suje- 
tos: trabajo, familia, relaciones sociales y costumbres. Aquí destaca la especial relevancia que le otorgan los hombres al ámbito laboral - en el cual manifiestan valerse de las ventajas que proporciona vivir en la frontera Estados Unidos/México para hacer crecer sus empresas o carreras profesionales- en contraste con las mujeres, que priorizan en sus discursos el grupo familiar como nodo articulador de una adaptación que no es meramente individual: la familia que se adapta. En cuanto a las relaciones sociales, sobresalen las dificultades al relacionarse con otros y otras integrantes de la comunidad argentina y una afinidad mayor con las y los mexicanos o mexicanamerican que con las personas de origen anglosajón, aunque en ocasiones también surgen fuertes diferenciaciones entre lo que las y los entrevistados perciben como rasgos de la idiosincrasia argentina y la mexicana. Finalmente, respecto de las costumbres, especialmente en torno a la alimentación y las formas del habla, se observan distintos grados de adaptación que van desde la incorporación plena de códigos propios de la/s cultura/s de incorporación hasta estrategias de negociación más activas, donde se ceden algunos rasgos y se mantienen otros de acuerdo a las necesidades y contextos.

A su vez, en todos los testimonios se advierte una profusa utilización de un argot relativo al cruce y a la frontera que es propio de la región y forma parte de aquello que aquí se denomina estilo de vida transfronterizo: desde la utilización de la palabra "línea" tanto como sinónimo del límite internacional como de la fila de personas que esperan para cruzarla, hasta la expresión "otro lado" en referencia a aquello que se encuentra allende la frontera internacional, o el manejo de términos propios de la administración legal de la práctica del cruce por parte del gobierno de Estados Unidos, como la "SENTRI" o la "revisión secundaria".

Los relatos y las experiencias de inmigrantes argentinos residentes a ambos lados de la frontera San Diego/Tijuana constituyen una novedad epistemológica para el campo de estudios sobre el fenómeno migratorio en esa región en dos sentidos. En primer lugar, hasta donde llega el conocimiento de los autores de este trabajo, no existe un solo artículo científico que dé cuenta de esta comunidad inmigratoria. A ello se suma que los datos censales solo permiten estimar la cantidad de argentinas y argentinos que residen en San Diego, no así en Tijuana. En segundo lugar, por integrar una comunidad minoritaria con sus referentes culturales propios, los discursos de estos hombres y mujeres aportan una sensibilidad cultural inusual 
en los estudios sobre esta región, dominado por los abordajes del ethos mexicano, estadounidense y mexican-american.

Al ser el estilo de vida transfronterizo un conjunto de códigos y prácticas encarnadas por una gran diversidad de actores, quienes lo practican le van incorporando ingredientes provenientes de distintos orígenes culturales, permeados por diferentes grados de identificación con esos orígenes y con la/s cultura/s de incorporación, todo lo cual resulta en un entramado de intercambios del que solo se conoce su parte más visible o evidente, pero queda mucho aún por descubrir. Esto ayuda a desnaturalizar concepciones rígidas acerca de las características propias de este enclave, que ciertamente es modelado principalmente por las comunidades mexicana y estadounidense y sus variantes e interconexiones, pero también es permanentemente resignificado a la luz de otros referentes, por inmigrantes procedentes de otros contextos geográficos y culturales que han elegido este lugar para vivir.

A la luz de este tipo de dinámicas, conceptos concebidos pensando en realidades de escala global, como transnacional, espacio transnacional y migración transnacional, ciudadanías post-nacionales o circularidad migratoria, pierden potencia explicativa y se hace necesario reflexionar sobre la posibilidad de nuevas categorías teórico-conceptuales de menor alcance y mayor precisión. Parte de estas y estos inmigrantes argentinos se vinculan doblemente con el fenómeno migratorio: mantienen relaciones transnacionales con sus familiares y amigos en Argentina, pero también transfronterizos de corto alcance con sus referentes en San Diego o Tijuana. En un determinado año, han podido cruzar varias veces una frontera internacional — que para ellas y ellos tiene una significación local—para visitar a familiares, clientes, proveedores o amistades y ocasionalmente, también, han cruzado una frontera internacional de largo alcance para viajar a su país de origen. Esto ejemplifica la necesidad de distinguir en los análisis migratorios entre experiencias transfronterizas [movilidad local/internacional] y transnacionales [movilidad internacional supra-local]. No es el objetivo de este artículo avanzar específicamente en esa tarea, aunque se espera haber contribuido a la discusión ilustrando algunas implicancias y alcances del estilo de vida transfronterizo y los modos en que inmigrantes que integran una comunidad minoritaria son capaces de adaptarse y contribuir a él activamente. 


\section{REFERENCIAS BIBLIOGRÁFICAS}

Alegría, T. (2005). Tijuana, México. Integration, Growth, Social Structuring and Governance References. En M. Balbo (Ed.), International Migrants and the City (pp. 258-266). Venecia: UN-Habitat. Recuperado de https:// unhabitat.org/books/international-migrants-and-the-city/

Alonso, G. (2009). Janos identitarios, centauros culturales. Estudiantes transfronterizos de Tijuana en San Diego como una realidad mexicana incómoda. En H. Padilla \& C. Pequeño (Coord.), Cultura e Identidad en la frontera México-Estados Unidos (pp. 71-97). Ciudad Juárez: UACJ.

Alonso, G. (Coord.). (2016). Fronteras simbólico-culturales, étnicas e internacionales. Tijuana: El Colef.

Anderson, B. (1983). Imagined Communities. Reflections on the Origin and Spread of Nationalism. Londres/Nueva York: Verso.

Basok, T. (2004). Post-National Citizenship, Social Exclusion, and Migrants' Rights: Mexican Seasonal Workers in Canada. Citizenship Studies, 8(1), 47-64. https://doi.org/10.1080/1362102042000178409

Baumann, M., Lorenz, A., \& Rosenow, K. (Edits.) (2011). Crossing and Controlling Borders. Immigration Policies and their Impact on Migrants' Journey. Leverkusen, Alemania: Budrich Unipress.

Blanco, C. (2000). Las migraciones contemporáneas. Madrid: Alianza Editorial.

Caggiano, S. (2007). Madres en la frontera: género, nación y los peligros de la reproducción. Íconos, 28, 93-106. https://doi.org/10.17141/iconos.28.2007.220

Castells, M. (2009). Comunicación y poder. Madrid: Alianza Editorial.

Castles, S., Ozkul, D., \& Arias Cubas, M. (Eds.). (2015). Social Transformation and Migration. National and Local Experiences in South Korea, Turkey, Mexico and Australia, Londres: Palgrave Macmillan.

Ceballos, M. (Coord.). (2001). Encuentro en la frontera: mexicanos y norteamericanos en un espacio común. México: Colmex/Colef/UAT.

Dahrendorf, R. (1996). La cuadratura del círculo. Bienestar económico, cohesión social y libertad política. Ciudad de México: FCE.

Glick-Schiller, N., Basch, L., \& Szanton-Blanc, C. (Eds.) (1992). Towards a Transnational Perspective on Migration: Race, Class, Ethnicity, and $\mathrm{Na}$ tionalism. Nueva York: New York Academy of Sciences.

Grimson, A. (2000). El puente que separó dos orillas. Notas para una crítica del esencialismo de la hermandad. En A. Grimson (Comp.), Fronteras, naciones e identidades. La periferia como centro (pp. 201-231). Ciccus-La Crujía, Buenos Aires.

Hernández, R., Fernández, C., \& Baptista, P. (2006). Metodología de la investigación. México: McGraw-Hill.

Herzog, L. (2000). Cross-Border Planning and Cooperation. En P. Ganster (Ed.), The U.S.-Mexican Border Environment (pp. 139-161). San Diego: SDSU Press. 
Herzog, L. (2003). The Political Economy of Tourism Development in the San Diego-Tijuana Transfrontier Metropolis. En D. R. Judd (Ed.) The Infrastructure of Play: Building the Tourist City (pp. 215-245). Armonk, Nueva York: M. E. Sharpe.

Herzog, L. (2009). Global Crossroads: Planning and Infrastructure for the California-Baja California Border Region. San Diego: Trans Border Institute, USD.

Herzog, L. (2015). Global Suburbs: Urban Sprawl from the Rio Grande to Rio de Janeiro. Londres/Nueva York: Routledge.

Herzog, L., \& Sohn, C. (2014). The Cross-Border Metropolis in a Global Age: A Conceptual Model and Empirical Evidence from the US-Mexico and European Border Regions. Global Society, 28(4), 441-461. https://doi.org $/ 10.1080 / 13600826.2014 .948539$

Heyman, J. (2011). Cuatro temas en el estudio de la frontera contemporánea. En N. Ribas (Ed.), El Río Bravo Mediterráneo. Las regiones fronterizas en la época de la globalización (pp. 81-97). Barcelona: Bellaterra.

ICE (Immigration and Customs Enforcement) (2017). Removals statistics. Recuperado de https://www.ice.gov/removal-statistics/2017

INEGI (Instituto Nacional de Estadística y Geografía) (2019). Proyección de población 2020. Recuperado de https://www.inegi.org.mx/

IOM (International Organization for Migration) (2011). Glossary on Migration. Ginebra: IOM.

Karasik, G. A., \& Benencia, R. (1998). Apuntes sobre la migración fronteriza. Trabajadores bolivianos en Jujuy. Estudios Migratorios Latinoamericanos, 40/41, 569-594.

Kralich, S., Benedetti, A., \& Salizzi, E. (2012). Aglomeraciones transfronterizas y movilidad. Una aproximación desde casos sudamericanos. Boletim Gaúcho de Geografia, 38, 111-136.

Levitt, P. (2009). Roots and Routes: Understanding the Lives of the Second Generation Transnationally. Journal of Ethnic and Migration Studies, 35(7), 1225-1242. https://doi.org/10.1080/13691830903006309

López, A., \& Godenau, D. (2015). En torno a la Circularidad Migratoria: Aproximaciones conceptuales, Dimensiones teóricas y Práctica Política. Migraciones, 38, 9-34. https://doi.org/10.14422/mig.i38y2015.001

Mallimacci, F., \& Giménez, V. (2006). Historia de vida y métodos biográficos. En I. Vasilachis (Coord.), Estrategias de investigación cualitativa (pp. 175-212). Barcelona: Gedisa.

Nieswand, B. (2011). Theorising Transnational Migration: The Status Paradox of Migration. New York and London: Routledge.

Novick, S. (Ed.). (2007). Sur-Norte. Estudios sobre la emigración reciente de argentinos. Buenos Aires: Catálogos.

Passel, J., \& D’Vera, C. (2011). Unauthorized Immigrant Population: National and State Trends, 2010. Washington, D. C. Pew Hispanic Center Research Center, 1 de febrero. Recuperado de www.pewhispanic.org/2011/02/01/ unauthorized-immigrant-population-brnational-and-state-trends-2010 
Portes, A., Guarnizo, L. E., \& Landolt, P. (1999) The study of transnationalism: pitfalls and promise of an emergent research field. Ethnic and racial studies, 22(2), 217-237. https://doi.org/10.1080/014198799329468

Renoldi, B. (2014). Tus amigos son mis amigos: agentes y Estado en un paso de frontera argentino. Alteridades, 24(47), 89-100.

Ribas, N. (Ed.). (2011). El Río Bravo Mediterráneo. Las regiones fronterizas en la época de la globalización. Barcelona: Bellaterra.

Sassen, S. (2009). Bordering capabilities versus borders: implications for national borders. Michigan Journal of International Law, 30(3), 567597. Recuperado de http://repository.law.umich.edu/cgi/viewcontent. cgi? article $=1127 \&$ context $=$ mjil

Sautu, R. (1999). Recuerdos de infancia: cómo se entrena a las niñas en el servicio doméstico. En R. Sautu (Comp.), El método biográfico. La reconstrucción de la sociedad a partir del testimonio de los actores (pp. 101120). Buenos Aires: Editorial de Belgrano.

Segato, R. (2007). La Nación y sus Otros. Raza, etnicidad y diversidad religiosa en tiempos de Políticas de la Identidad. Buenos Aires: Prometeo.

US CENSUS BUREAU (United States Census Bureau) (2010). 2010 Census, Recuperado de https://www.census.gov/

Van Houtum, H., \& Van der Velde, M. (2004). The Power of Cross-Border Labour Market Immobility. Tijdschrift voor Economische en Sociale Geografie, 95(1), 100-107. https://doi.org/10.1111/j.0040-747X.2004.00296.x

Vertovec, S. (2009). Transnationalism. Londres: Routledge.

Vila, P. (2000). Crossing Borders, Reinforcing Borders: Social Categories, Metaphors, and Narrative Identities on the U.S.-Mexico Frontier. Austin, Texas: University Press.

Vila, P. (2001). Versión estadounidense de la teoría de frontera: una crítica desde la etnografía. Papeles de población, 7(30), 11-30. Recuperado de http://www.scielo.org.mx/scielo.php?script=sci_arttext\&pid $=$ S1405-74252001000400002 \&lng = en\&tlng =

Waldinger, R. (2015). The Cross-border Connection: Immigrants, Emigrants, and Their Homelands. Cambridge, Massachusetts: Harvard University Press.

Wimmer, A., \& Glick Schiller, N. (2002). Methodological nationalism and beyond nation-state building, migrations and the social sciences. Global Networks, 2(4), 301-334. https://doi.org/10.1111/1471-0374.00043 